\title{
THE PHYSICAL METALLURGY OF CAST AND WROUGHT ALLOY 718
}

\author{
John F. Radavich \\ School of Materials Engineering \\ Purdue University
}

\begin{abstract}
The physical metallurgy of cast and wrought alloy 718 is discussed in terms of the importance of $\mathrm{Nb}$ on the phase reactions found in alloy 718. The role or influence of $\mathrm{Nb}$ is first noted during the solidification of alloy 718 as the large atoms $\mathrm{Nb}$, Mo, and Ti segregate to the interdendritic regions where the $\mathrm{Nb}$ rich Laves phase forms. The Laves phase must be solutioned at high temperatures and the $\mathrm{Nb}$ must be distributed throughout the dendrite areas.

The normal phases found in alloy 718 are the MC, TiN, delta, Laves, $\gamma^{\prime \prime}$ and $\gamma^{\prime}$. The $\gamma^{\prime \prime}$ and $\gamma$ are the main strengthening phases and their precipitation behavior is determined primarily by the amount of $\mathrm{Nb}$, the temperature and time of exposure. Any incomplete homogenization of the cast or wrought material will produce non-uniform precipitation of the delta, $\gamma^{\prime}$ and $\gamma$ phases during working or aging heat treatments.

The longtime stability of alloy 718 is related to the stability of the $\gamma^{\prime \prime}$ phase which transforms to delta and $\gamma^{\prime}$ with increasing time and temperatures. Eventually the $\gamma$ phase will solution and the delta phase becomes the terminal phase in the 718 system. An $\alpha \mathrm{Cr}$ phase is found in the grain boundaries in long time exposures in the $1100^{\circ}-1350^{\circ} \mathrm{F}$ temperature range. The $\mathrm{M}_{23} \mathrm{C}_{6}$ carbide phase normally found in $\mathrm{Ni}$ base alloys is not found in alloy 718 .

\section{Introduction}

Alloy 718 was developed by the International Nickel Company in the 1950's and is currently used in cast, wrought, and powder forms. Many of the early structural studies were carried out on wrought material whose thermal histories prior to heat treatment were unknown. The precipitation found in many of these samples was not uniform and the significance of nonuniform precipitation was not recognized until recently. Many fine structural studies have been carried out in the past and it is not the intent of this paper to dwell on the results of early studies but, based on recent studies, possibly explain the reasons for the wide range of structural behavior of the phases found in current cast and wrought alloy 718 .

The nominal composition of alloy 718 is $18 \mathrm{Fe}, 18 \mathrm{Cr}, 3 \mathrm{Mo}, 5 \mathrm{Nb}, 1 \mathrm{Ti}, 0.5 \mathrm{Al}, .04 \mathrm{C}$, and $.004 \mathrm{~B}$. The phases reportedly found in alloy 718 are $\mathrm{Nb}$, TiC, TiN, delta, Laves, $\gamma, \gamma^{\prime \prime}, \alpha \mathrm{Cr}$, sigma, and $\mathrm{M}_{6} \mathrm{C}$. The $\mathrm{Cr}_{23} \mathrm{C}_{6}$ and $\mathrm{M}_{3} \mathrm{~B}_{2}$ phases have not been found in conventional alloy 718 materials. The sigma and $\mathrm{M}_{6} \mathrm{C}$ phases found in early structural studies are attributed to two factors: the high silicon levels of early heats and because early samples were exposed to initial solution temperatures of $2200^{\circ} \mathrm{F}$ or higher. Because of controlled Si contents and lower temperatures used for homogenization, these phases are no longer found.

Superalloy 718-Metallurgy and Applications Edited by E.A. Loria

The Minerals, Metals \& Materials Society, 1989
\end{abstract}




\section{Strengthening Phases}

The major strengthening phases in alloy 718 are the $\gamma^{\prime \prime}$ and $\gamma$ phases which produce coherency strains in the $\gamma$ matrix. The $\gamma^{\prime}$ phase is considered to be the main strengthening phase and has a $\mathrm{DO}_{22} \mathrm{BCT}$ crystal structure while the $\gamma^{\prime}$ is a $\mathrm{FCC}$ ordered phase with a $\mathrm{Ll}_{2}$ crystal structure. While both the $\gamma^{\prime \prime}$ and $\gamma$ formulas contain 3 atoms of $\mathrm{Ni}$, the $\gamma^{\prime \prime}$ phase is richer in $\mathrm{Nb}$ while the $\gamma$ phase is richer in Al. The dependence of the $\gamma^{\prime}$ more on the $\mathrm{Nb}$ content affects its precipitation behavior as will be discussed later.

The $\gamma^{\prime \prime}$ and $\gamma$ phases have unique morphologies which sometimes helps to identify the phases. The $\gamma$ phase precipitates as a round particle whose size can be less than $200 \AA$ and continues to be round in shape when it coalesces at higher temperature. The $\gamma^{\prime \prime}$ phase has more of a disk shape nature whose length is 5 to 6 times its thickness; however, when the $\gamma^{\prime \prime}$ precipitates at very low temperatures, a TEM is necessary to resolve its shape. The $\gamma^{\prime \prime}$ phase continues to grow in the disk shape at higher heat treat temperatures or exposures. Some studies have indicated that the $\gamma^{\prime}$ and $\gamma$ phases grow in a sandwich-like morphology indicating a co-precipitation of the phases.

Because the $\gamma^{\prime \prime} / \gamma^{\prime}$ phases grow with higher temperatures and long time exposures at low temperatures, a transition of $\gamma$ to $\gamma^{\prime \prime}$ to delta phase occurs slowly at the lower temperatures, but the reaction occurs faster or sooner at the higher temperatures. Recent data to be reported in another paper has indicated that the $\gamma^{\prime \prime}$ is the least stable phase and the transition is $\gamma^{\prime \prime}$ to delta and $\gamma$.

The delta phase found in alloy 718 is incoherent with the $\gamma$ and has an orthorhombic crystal structure. The delta phase is found mostly as plates growing on the (111) planes or nucleating on the grain boundaries and is associated with loss of strength in this alloy. As will be discussed later in the paper, the delta phase in the grain boundaries is used to control grain size in wrought materials and seems to be also important for notch ductility.

\section{Phase Precipitation Ranges}

A number of T-T-T (time-temperature-transformation) diagrams have been published for alloy 718 by Eiselstein, Decker, and others. While there are some differences found in the extent of the temperature ranges, it is apparent that the delta phase precipitates in an approximate temperature range of $1600^{\circ} \mathrm{F}$ to $1850^{\circ} \mathrm{F}, \gamma^{\prime}$ forms in a range of $1300^{\circ} \mathrm{F}$ to $1650^{\circ} \mathrm{F}$, and $\gamma^{\prime}$ precipitates at temperatures of $1100^{\circ} \mathrm{F}$ to $1300^{\circ} \mathrm{F}$. There is generally more than one phase present as there is a temperature overlap for the phases due to the transition of one phase to the other with increasingly higher temperatures of exposure.

The primary $\mathrm{MC}$ and the TiN phases in alloy 718 are generally considered to be stable phases and will not change with thermal cycles at lower temperatures. On the other hand, the presence of the Laves phase reported in early literature in wrought materials is a result of incomplete homogenization of the alloy prior to final heat treatments.

\section{Phase Composition and $\mathrm{Nb}$ Contents}

A number of structural studies on modified alloy 718 compositions with varying amounts of $\mathrm{Nb}, \mathrm{Cr}$, and $\mathrm{Fe}$ coupled with $\mathrm{X}$-ray chemical analyses have shown that a correlation exists between the amount of $\mathrm{Nb}$, the kind of phase stability, and the temperature range of precipitation. It has been found that Laves phase requires $10-12 \% \mathrm{Nb}$ to form, the delta phase requires $6-8 \% \mathrm{Nb}$, the $\gamma^{\prime \prime}$ needs $4 \% \mathrm{Nb}$, and the $\gamma$ can form with $\mathrm{Nb}$ levels below $4 \% \mathrm{Nb}$. The normally accepted ranges for precipitation of $\gamma^{\prime \prime}, \gamma$, and delta phases can be changed depending on the amounts of $\mathrm{Nb}$ present.

\section{Cast Alloy 718}

To better understand the structural responses in cast and wrought 718 , it is necessary to better understand and appreciate the role of $\mathrm{Nb}$ segregation on phase reactions. The extent of $\mathrm{Nb}$ segregation during ingot or casting solidification is related to the rate of cooling and the ease with which the atoms can diffuse, i.e., the faster the cool, the less the segregation.

During solidification, the $\gamma$ matrix rejects selectively the large atoms of such elements as $\mathrm{Nb}, \mathrm{Mo}, \mathrm{Ti}$ to the interdendritic regions. These clements form the $\mathrm{NbC}, \mathrm{TiN}$, and the $\mathrm{Nb}$ 
rich Laves phase in the high $\mathrm{Nb}$ areas as the metal solidifies from about $2300^{\circ} \mathrm{F}$ to about $2000^{\circ} \mathrm{F}$. As the alloy cools in this temperature range, plates of delta phase start to form at about $2100^{\circ} \mathrm{F}$ near the interdendritic areas where the $\mathrm{Nb}$ content is still high. The delta formation will continue to about $1500^{\circ} \mathrm{F}$ or until the $\mathrm{Nb}$ content is too low for nucleation and growth. In those areas where the $\mathrm{Nb}$ content diminishes to $4 \%$, the $\gamma^{\prime \prime}$ phase will precipitate and continue to do so until about $1300^{\circ} \mathrm{F}$. Below the $4 \% \mathrm{Nb}$ level and below $1300^{\circ} \mathrm{F}$, the more stable $\gamma$ phase will precipitate if the material cools sufficiently slow. Thus, a whole range of phases will be present in the as-cast condition.

The Laves phase appears as islands and contains about $25 \% \mathrm{Nb}$ and forms preferentially in the interdendritic areas where high $\mathrm{Nb}$ levels exist. The formation of Laves phase is enhanced by the presence of Mo and Si. Since the Laves phase is detrimental to mechanical properties and depletes the matrix of $\mathrm{Nb}$ needed for $\gamma^{\prime \prime}$ and $\gamma^{\prime}$ precipitation, the thermal treatments during homogenization are critical.

Basically cast alloy 718 is heavily segregated and consists of two compositions: the dendrites which are very high in $\mathrm{Fe}, \mathrm{Cr}$, and $\mathrm{Ni}$ while the interdendritic areas are very rich in $\mathrm{Nb}, \mathrm{Mo}$, and $\mathrm{Ti}$. Chemical analyses show that dendritic $\mathrm{Nb}$ contents are as low as $2 \%$ while $\mathrm{Nb}$ levels in the interdendritic regions can range as high as $12 \%$. The homogenization cycle is the key to producing a uniform material for forging, etc.

\section{Homogenization}

Depending on the degree of segregation produced in the ingot or casting, high temperature homogenization cycles will vary but each must eventually solution the Laves phase and promote sufficient diffusion of $\mathrm{Nb}$ into dendritic areas without the use of deformation. Because Laves phases of different compositions can form with different solvus temperatures, care must be used to avoid rapid heating up to $2125^{\circ} \mathrm{F}$ (normal solvus temperature of Laves) to prevent incipient melting at the grain boundaries. Total homogenization consists of Laves phase solutioning and uniform $\mathrm{Nb}$ distribution. While the Laves can be completely solutioned, it may not be possible to economically have total uniform distribution of the $\mathrm{Nb}$.

Current technology of cast components utilizes a HIP cycle to close casting porosity and partly achieve homogenization. HIP parameters (time, temperature, pressure) will vary depending on the initial segregation and requirements for grain size control. Most HIP treatments are followed by post HIP solutioning step to dissolve the structures formed during HIP cool down and then are given a variety of intermediate and final aging cycles to produce $\gamma^{\prime}$ and $\gamma$ precipitation. Studies on HIPed structures versus solutioned only structures show a beneficial effect of the pressure in the HIP cycle.

Typical as-cast structures of fine and large grain castings are shown in Figures 1a and $1 \mathrm{~b}$. The SEM image shows a light and dark pattern whose size depends on the cooling rate. The light areas are high in $\mathrm{Nb}$ while the dark areas are low in $\mathrm{Nb}$. Higher magnification and resolution, Figures $2 a$ and $2 b$, shows the same samples with a variety of phases present in the interdendritic areas. The Laves islands are dark due to their response to sample preparation while the delta plates, $\gamma^{\prime}$, and $\gamma$ phases are light.

When cast material is heated to temperatures up to $2150^{\circ} \mathrm{F}$ and the Laves phase is solutioned, only the MC and TiN particles are visible. The phases produced during the ingot or casting cool down such as delta, $\gamma^{\prime \prime}$, and $\gamma$ phases are solutioned and do not have time to precipitate. However, non-uniform distribution of $\mathrm{Nb}$ carried over from the as-cast condition may still be present and can be brought out if the sample is given a "TAG" heat treatment $\left(1600^{\circ} \mathrm{F} / 1\right.$ hour), Figure $3 \mathrm{a}$ and $3 \mathrm{~b}$. Areas which have $4 \% \mathrm{Nb}$ or higher will precipitate a large $\gamma^{\prime \prime}$ phase while the grain boundaries will show the formation of delta plates. As the distribution of $\mathrm{Nb}$ becomes more uniform, the black and white pattern dendritic pattern diminishes.

During heat treatment at $1400^{\circ} \mathrm{F}$, the $\gamma^{\prime \prime}$ phase will precipitate quickly in the $\mathrm{Nb}$ rich areas but will be smaller in size than the $\gamma^{\prime}$ formed during the TAG treatment at $1600^{\circ} \mathrm{F}$. However, the black and white pattern will appear, but the pattern will not be as intense as that produced at $1600^{\circ} \mathrm{F}$, Figure 4. Areas low in $\mathrm{Nb}$ will not respond to $\gamma^{\prime \prime} / \gamma$ precipitation until lower temperatures are used. Samples given the standard $1325^{\circ} \mathrm{F}-1150^{\circ} \mathrm{F}$ aging cycle will precipitate out fine $\gamma^{\prime \prime}$ at $1325^{\circ} \mathrm{F}$ and $\gamma$ in the low $\mathrm{Nb}$ areas at the $1150^{\circ} \mathrm{F}$ temperature. Thus, precipitation of the $\gamma^{\prime} / \gamma$ phase will depend on the amount of $\mathrm{Nb}$ present, and the time and tempcraturc of aging. 


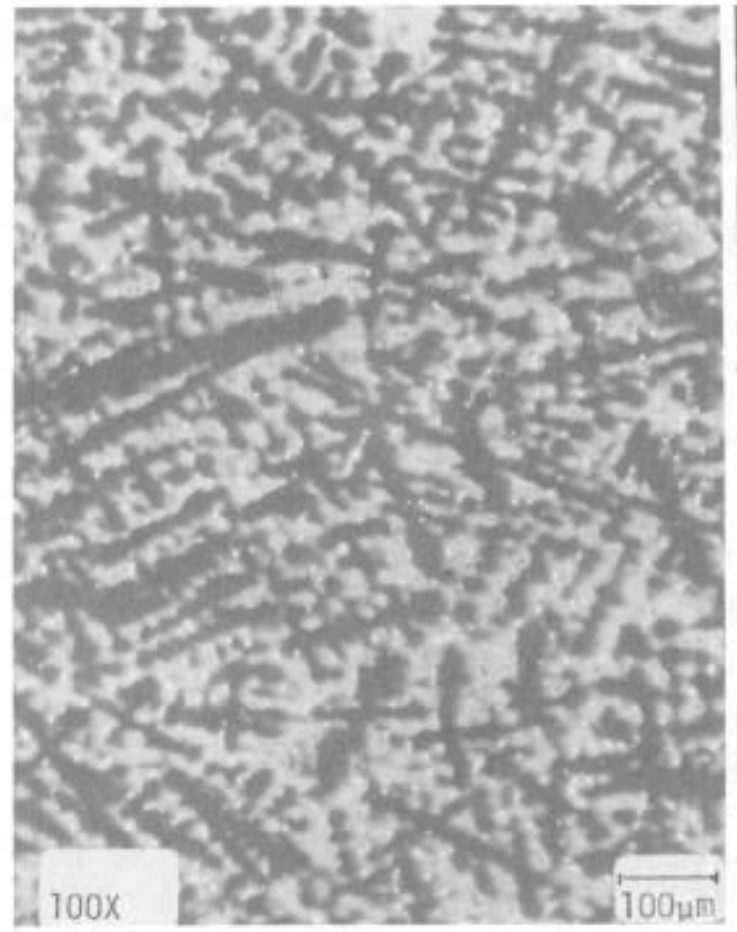

Fig. la. Fine Grain As-Cast.

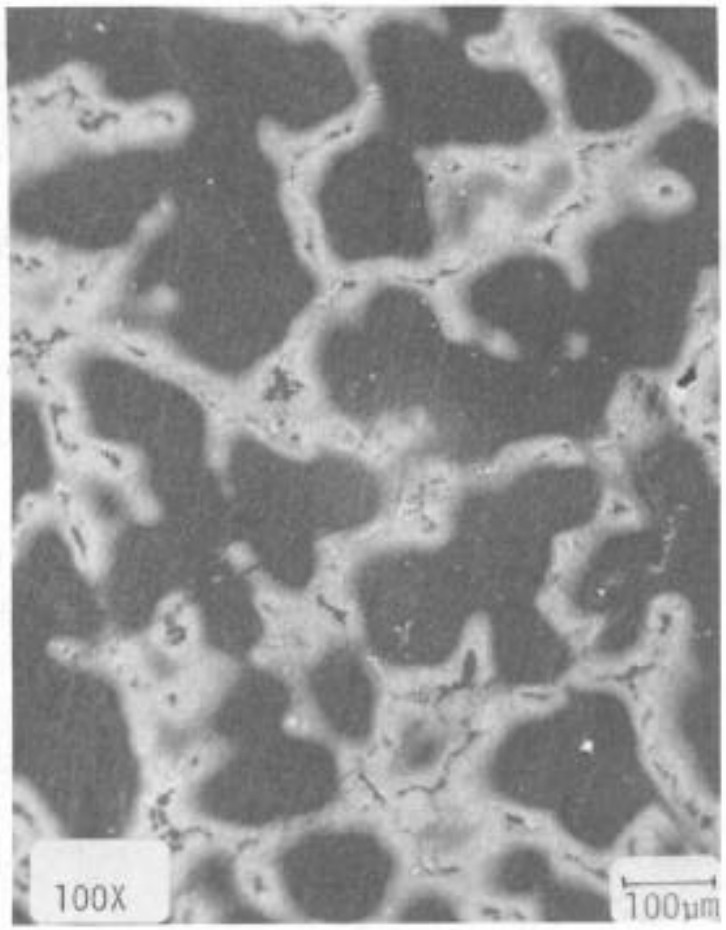

Fig. 1b. Large Grain As-Cast.

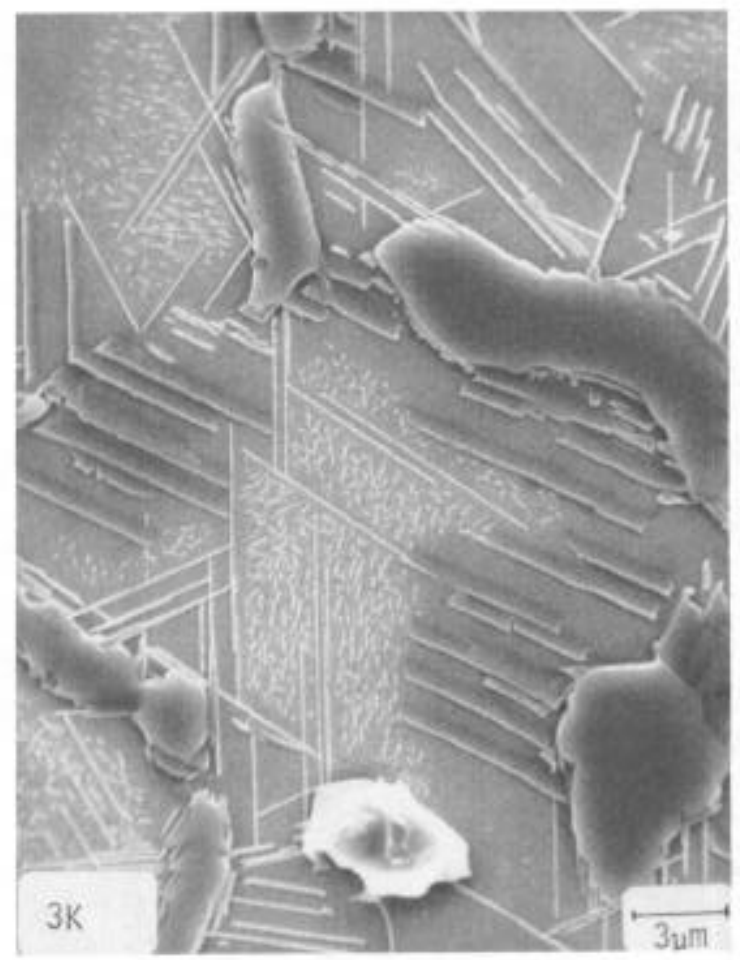

Fig. 2a. Fine Grain As-Cast.

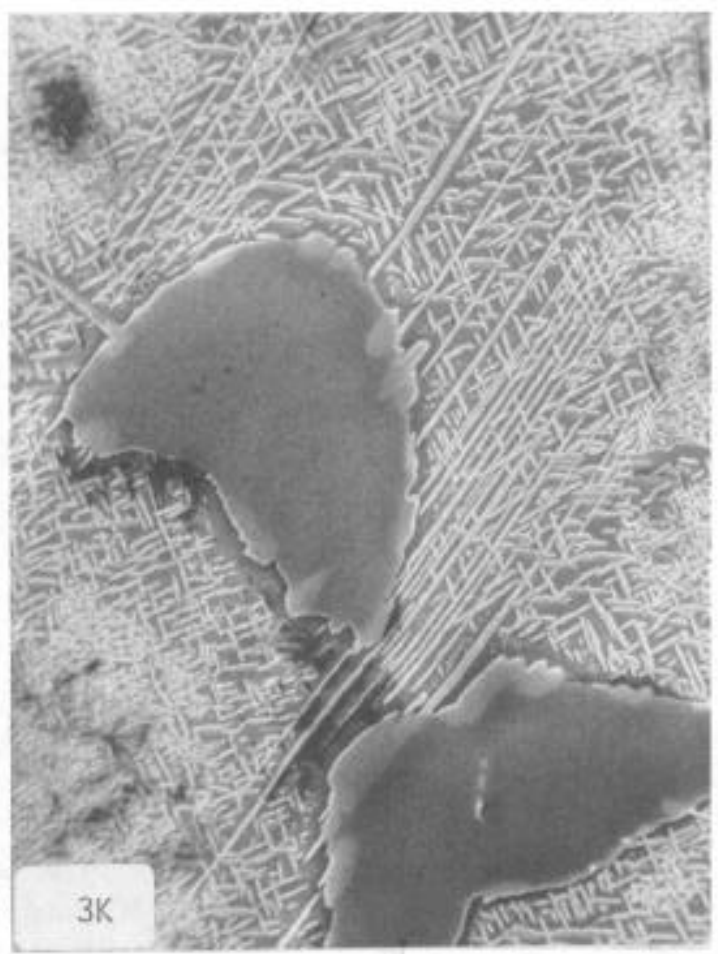

Fig. 2b. Large Grain A-Cast. 


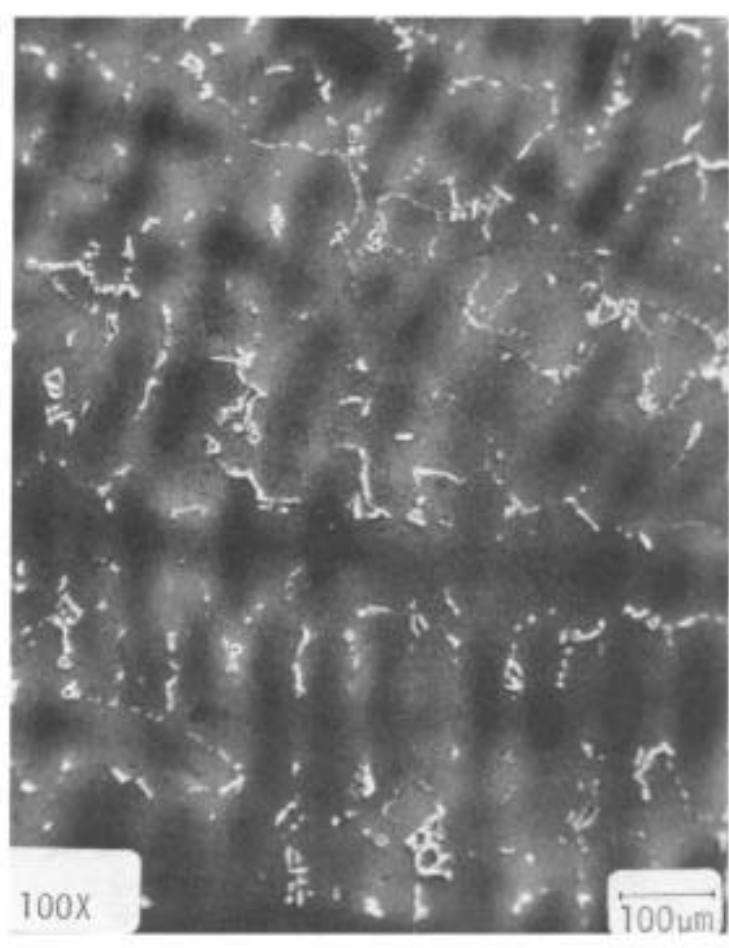

Fig. 3a. As-Cast+Sol' $\mathrm{n}+1600^{\circ} \mathrm{F} / 1 \mathrm{hr}$.

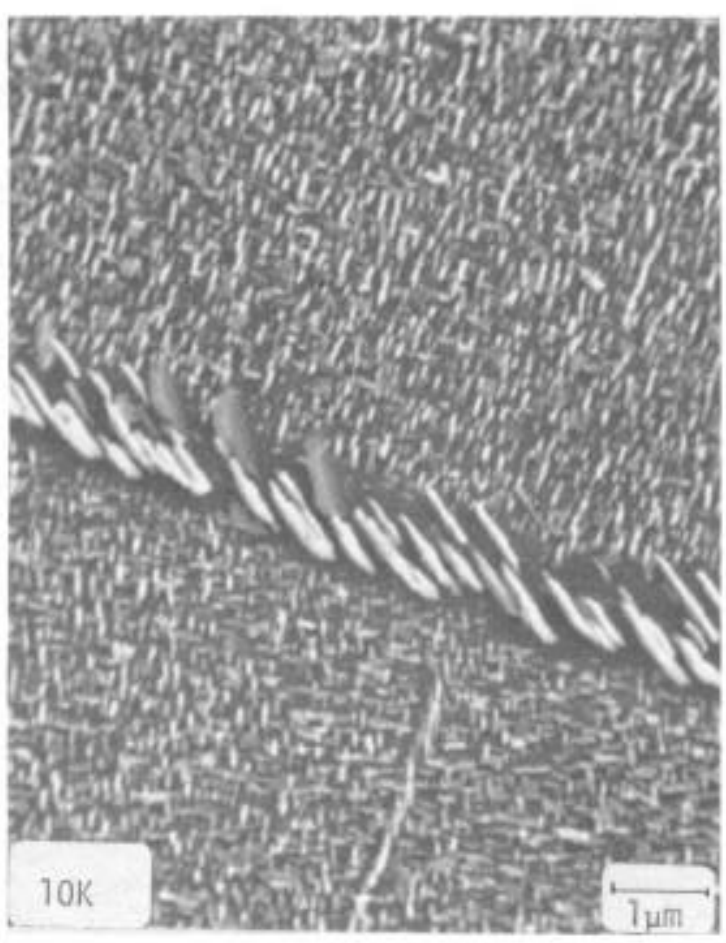

Fig. 3b. As-Cast $+\operatorname{Sol} 1^{\prime} \mathrm{n}+1600^{\circ} \mathrm{F} / 1 \mathrm{hr}$.

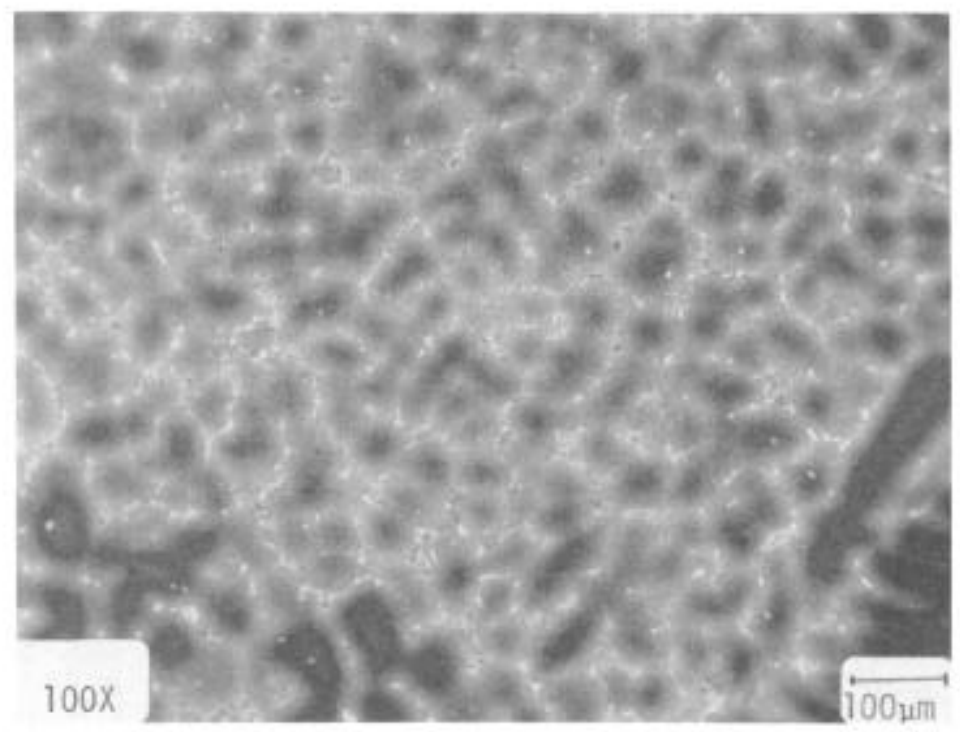

Fig. 4. As-Cast + Sol $\mathrm{n} n+1400^{\circ} \mathrm{F} / 5$ hrs. 
The Laves phase found in the as-cast condition should not be present after proper homogenization treatments. The presence of Laves phase in a homogenized sample indicates incomplete homogenization of the original $\mathrm{Nb}$ and subsequently, different precipitation responses will take place in the areas where the Laves phase is present.

\section{Stability of As-cast 718}

Very little has been published on the stability of cast 718 . In an earlier study, as-cast 718 was given only the standard low temperature heat treatment of $1325^{\circ} \mathrm{F}-1150^{\circ} \mathrm{F}$ and aged for 10,000 hours at $1100^{\circ} \mathrm{F}$. Except for $\gamma$ precipitation and growth, the segregation structures of delta and $\gamma^{\prime}$ were unaffected in 10,000 hours at this low temperature. The $\gamma$ structure formed during the low temperature aging cycle has grown in size and formed between the delta plates and the $\gamma^{\prime \prime}$ disks. The growth of the $\gamma$ in these regions is attributed to the very low Nb content as a result of the formation of $\mathrm{Nb}$ rich delta and $\gamma^{\prime}$ phases during solidification. Figure 5a shows the as-cast structure consisting of $\gamma^{\prime \prime}$ disks in the more $\mathrm{Nb}$ rich areas while small $\gamma$ precipitates are seen near the dendritic matrix. The matrix does not show any fine precipitation. Figure $5 b$ illustrates the fine precipitation of only $\gamma^{\prime}$ after the low temperature age. Figure $5 c$ shows the $\gamma^{\prime}$ growth in the low $\mathrm{Nb}$ areas near or between the delta and the $\gamma^{\prime \prime}$ precipitates after 10,000 hours at $1100^{\circ} \mathrm{F}$.

\section{Wrought Alloy 718}

Alloy 718 ingots must be soaked for long times prior to being processed to billet (to promote diffusion of $\mathrm{Nb}$ and to solution the Laves phase). Most of the conversion processes are proprietary, but generally involve some kind of "heat and beat" process and long soaking times depending on the degree of segregation present. When ingot diameters become too large or the original $\mathrm{Nb}$ content of the alloy is raised, $\mathrm{Nb}$ segregation and the presence of Laves phase at the ingot centers increase. Excessive areas of Laves and MC precipitation produced in the solidification show up as Freckles, Fig. 6. Center segregations may not respond to ordinary homogenization treatments and will be carried over into the final billet as Laves islands and/or delta phase banding after the normal mill anneal, Figure 7. The presence of Laves islands is cause for rejection of the material since additional homogenization cycles must be used prior to working and may not be successful for removal of the Laves islands. Laves islands are crack initiation sites and LCF life is impaired when Laves phase is present.

The use of the delta phase to pin down the grain boundaries during forging is well known. The $\delta$ solvus temperature is the key to grain size control. The delta phase solvus is controlled by the amount of $\mathrm{Nb}$ present in the billet prior to working the material. The solvus temperature is decreased as the $\mathrm{Nb}$ content is decreased, and areas low in $\mathrm{Nb}$ will undergo recrystallization and grain growth early in the processing and/or during solution heat treatment. If very fine grain structures are to be achieved, control of the homogeneity and knowledge of the $\delta$ solvus temperature of the starting matcrial is essential; otherwise, a number of larger grains will form and will be readily visible in the final product. Such large grains will give the appearance of "mini-white spots" in the etched sample and contribute to variations in mechanical properties.

In wrought 718 , the response of the $\gamma^{\prime \prime} / \gamma$ precipitation during the aging heat treatment is controlled by the temperatures of working, the amount of $\mathrm{Nb}$ present in the matrix, the amount of delta phase present and in addition, the amount of strain still left in the worked structure after the initial solution temperature. However, as a rule, the $\gamma^{\prime \prime} / \gamma$ precipitation in wrought 718 generally is mostly governed by the two variables described for cast 718 , i.e., the $\% \mathrm{Nb}$ and the temperature of aging. In the case of DA 718, the highly strained matrix and/or the fine recrystallized grains delays the precipitation of $\gamma^{\prime \prime} \gamma$ at the low temperatures of the standard heat treatment. In those cases where the precipitation cannot be readily seen with the SEM at magnifications of $10-30 \mathrm{~K}$, the TEM should be used for the detection of the precipitation. Figure 8 shows fine grain 718 at various magnifications and illustrates the difficulty of detecting the strengthening precipitations. The large number of thermal treatments imposed on alloy 718 to achieve specific mechanical properties attests to the complex nature of structural behavior dependence on the above variables.

\section{Phase Stability of Wrought 718}

The topic of phase stability in wrought 718 has been covered in detail elsewhere. During exposure and under stress, the delta phase grows at the expense of the $\gamma^{\prime \prime}$ phase and the strength 


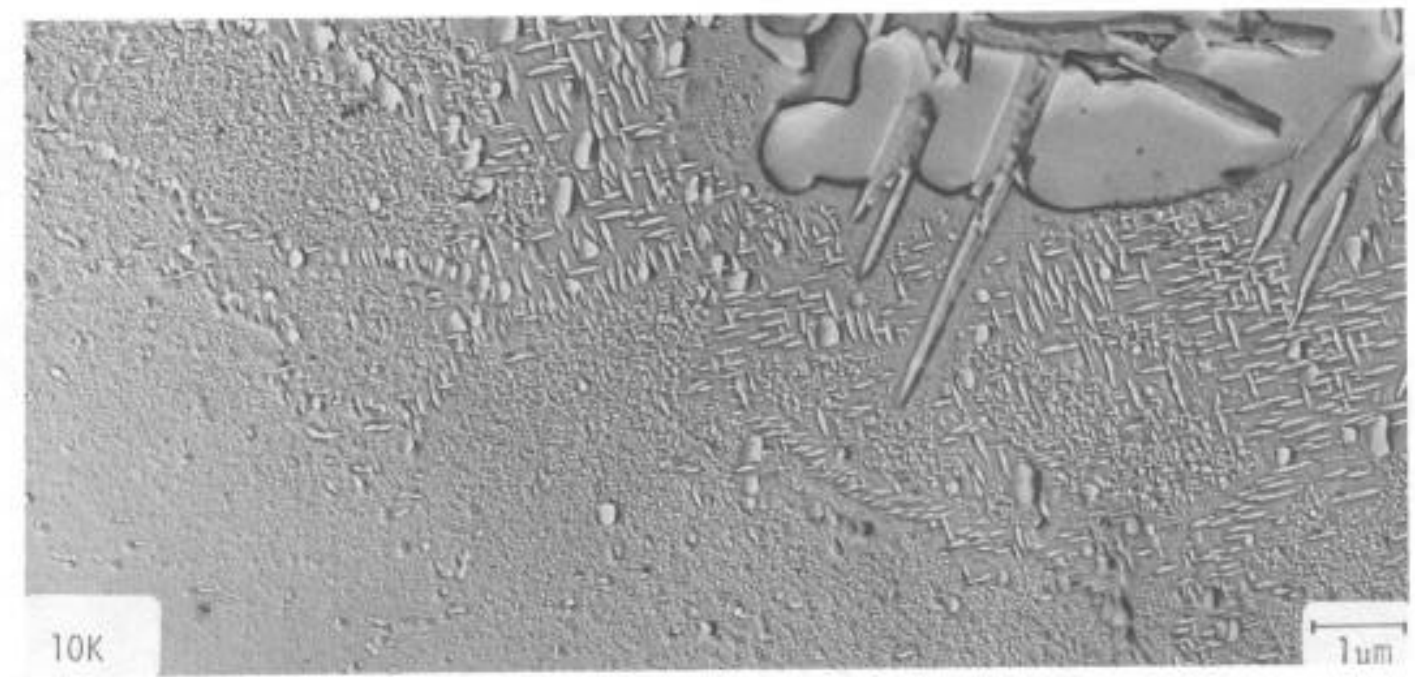

Fig. 5a. As-Cast.

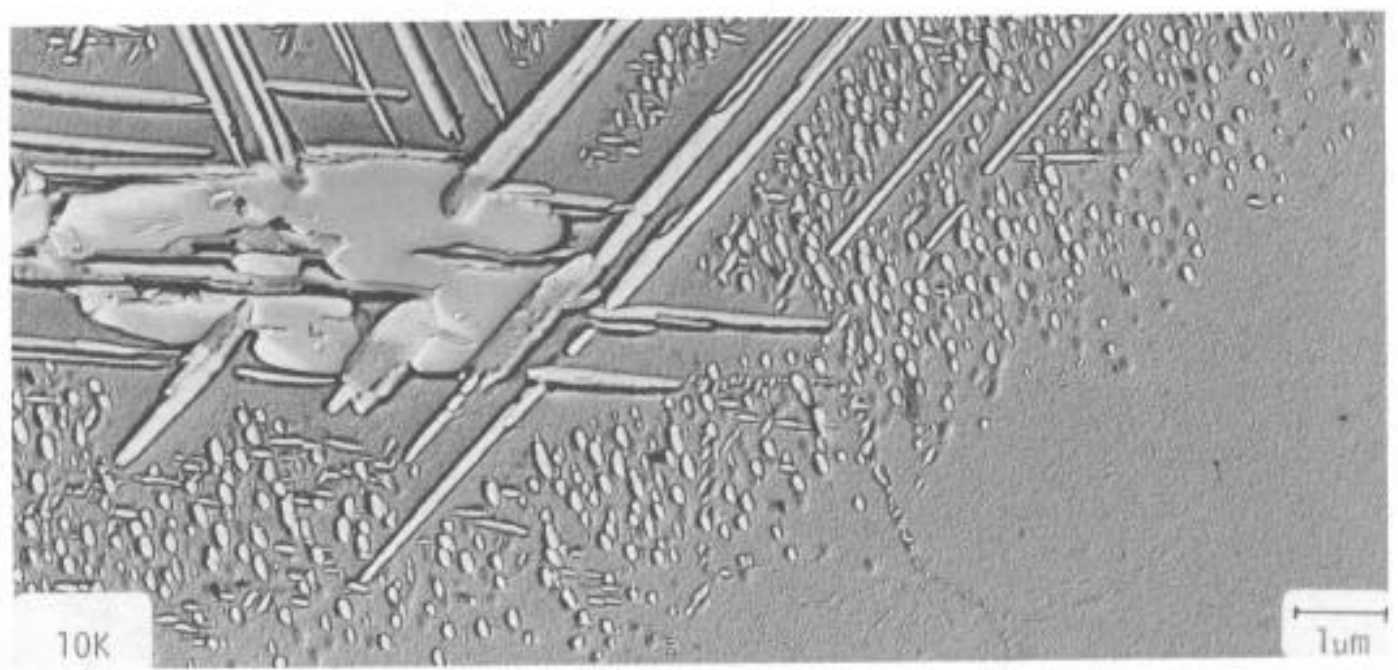

Fig. 5b. As-Cast + Heat Treatment.

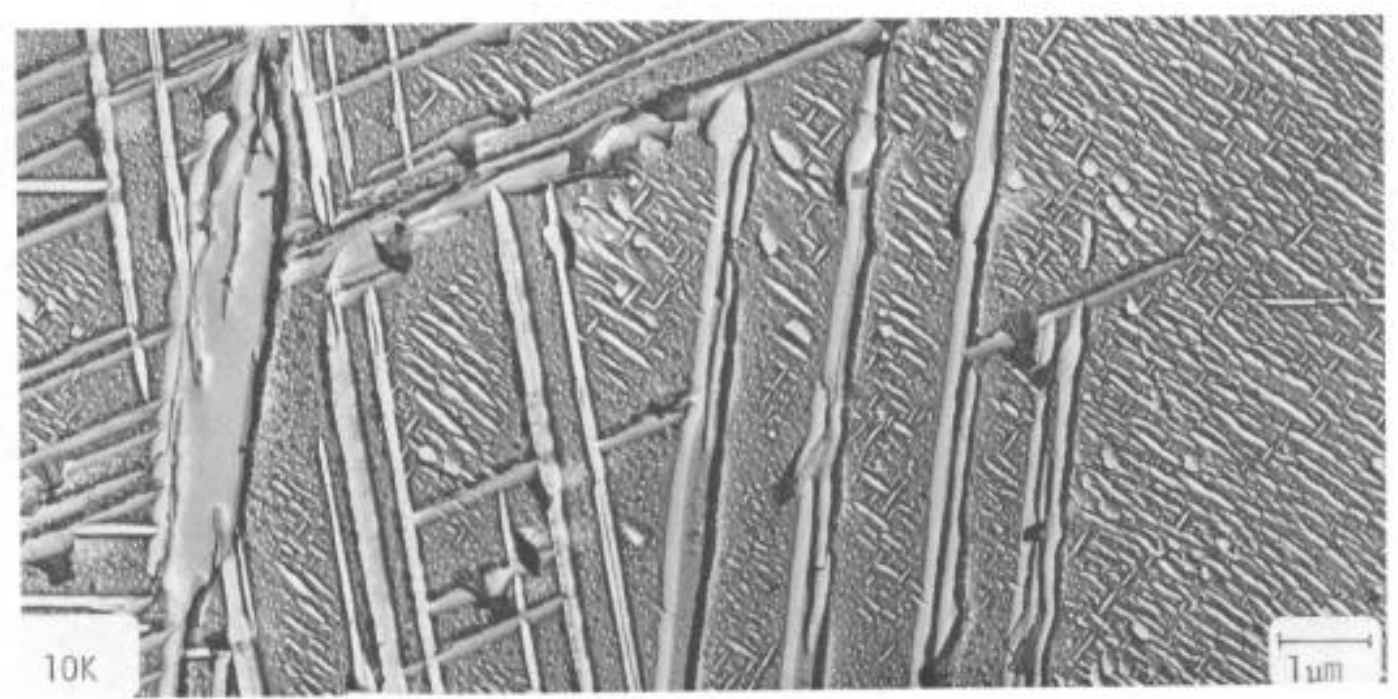

Fig. 5c. As-Cast $+\mathrm{HT}+1100^{\circ} \mathrm{F} / 10 \mathrm{~K}$ hrs. 


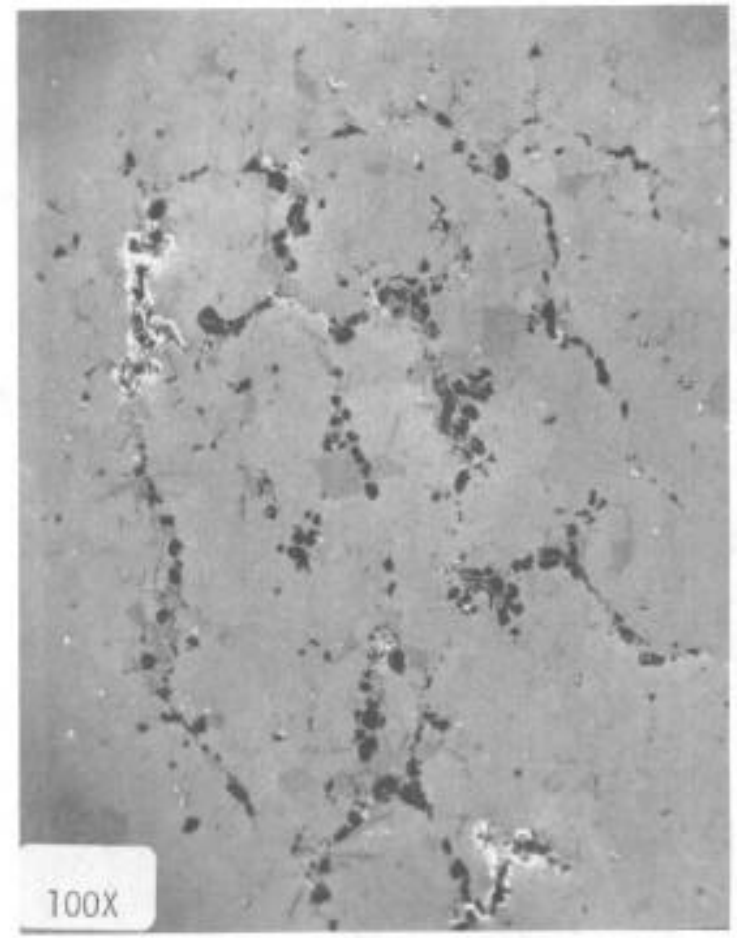

Fig. 6a. Freckles.

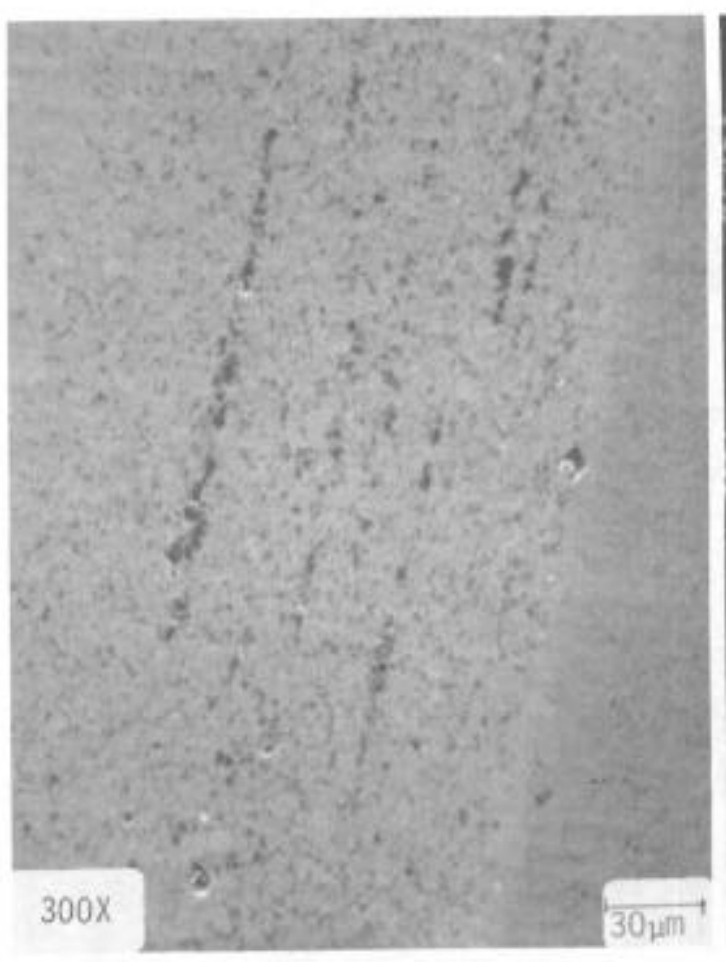

Fig. 7a. Laves Banding.

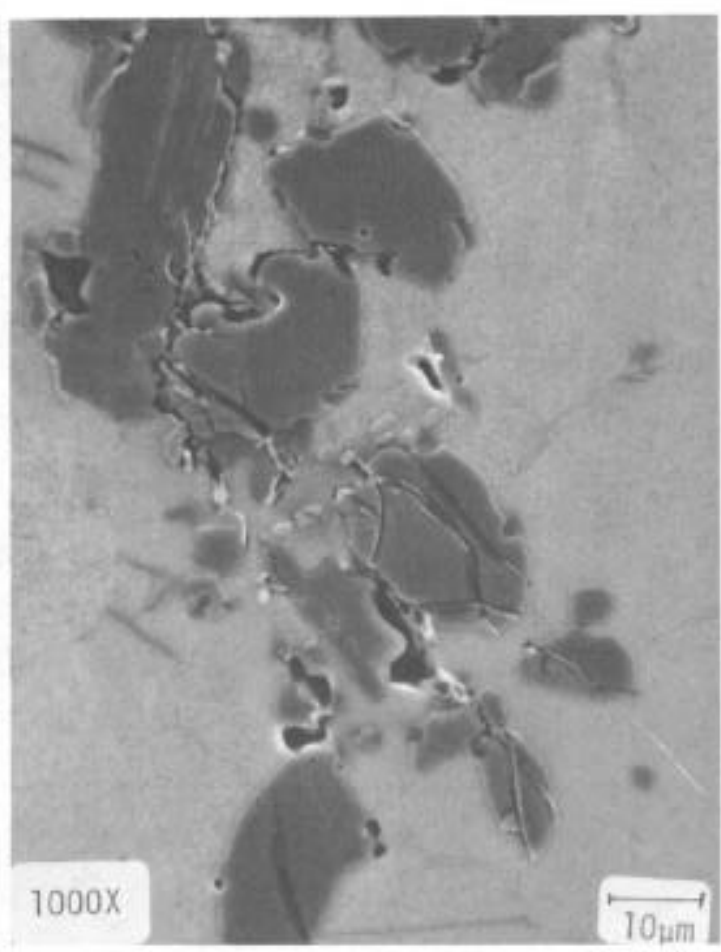

Fig. 6b. Freckles.

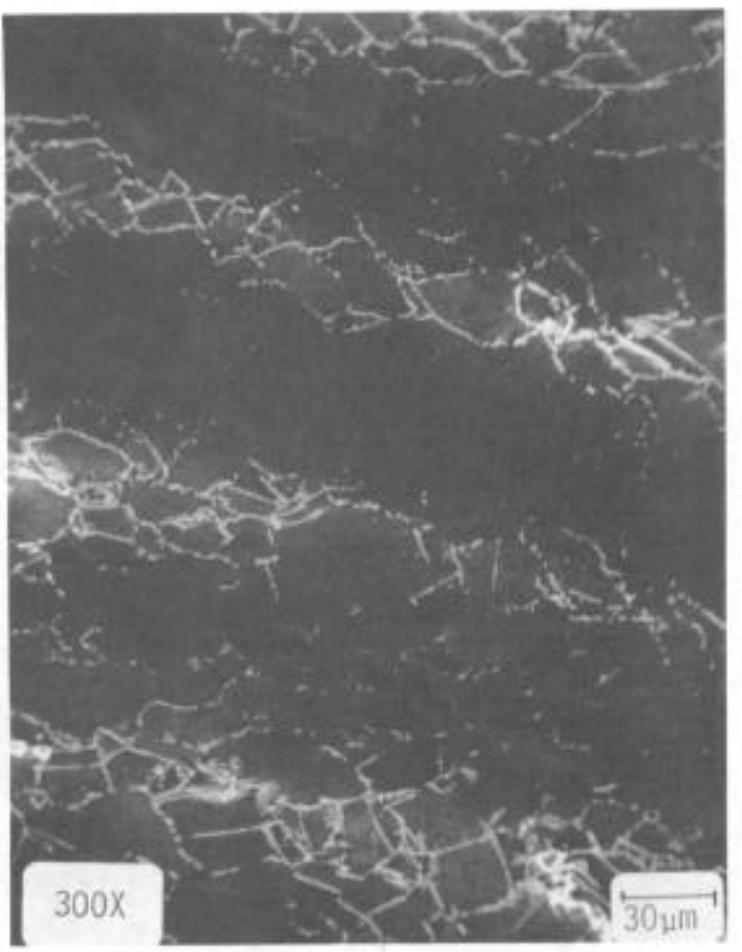

Fig. 7b. $\delta$ Phase Banding. 


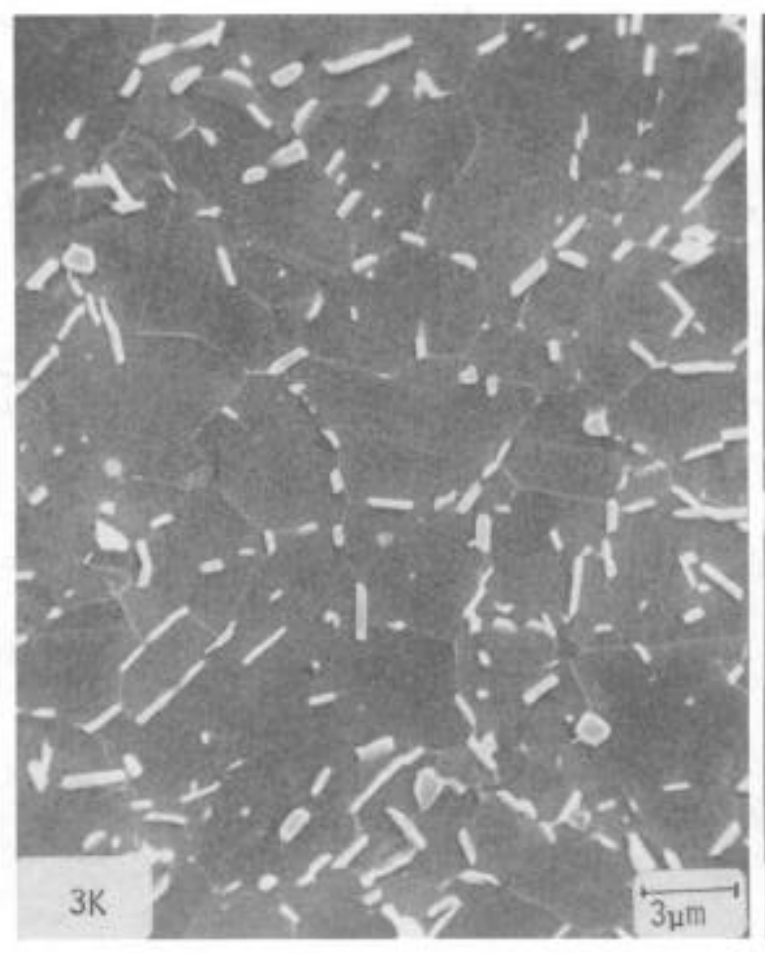

Fig. 8a. Fine Grain 718.

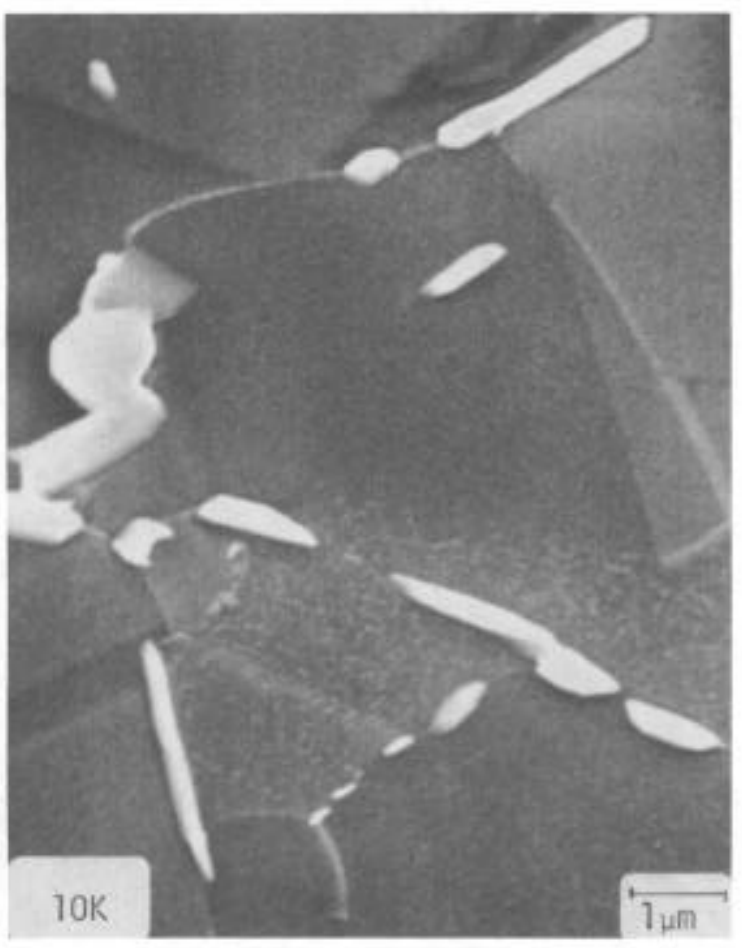

Fig. 8b. Fine Grain 718.

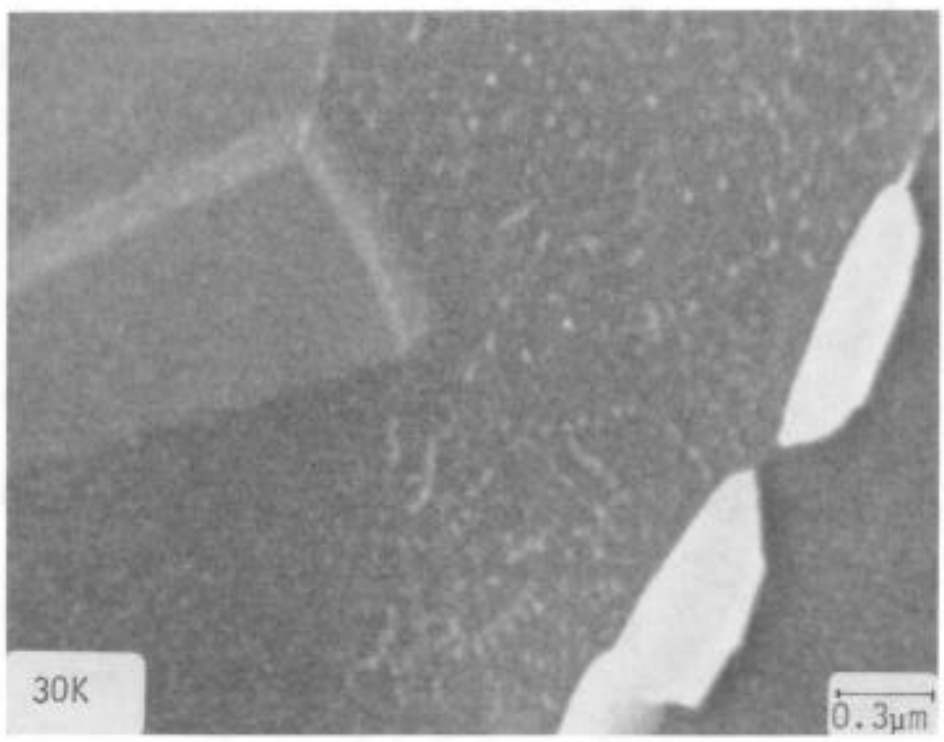

Fig. 8c. Fine Grain 718. 


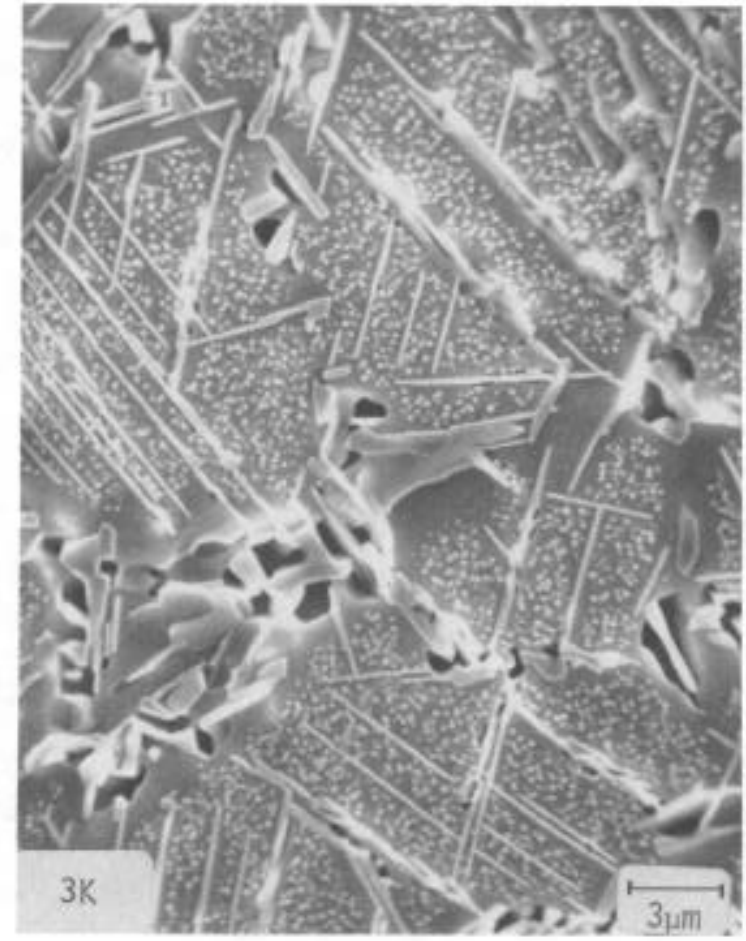

Fig. 9b. S/R $1350^{\circ} \mathrm{F} / 5000$ hrs.

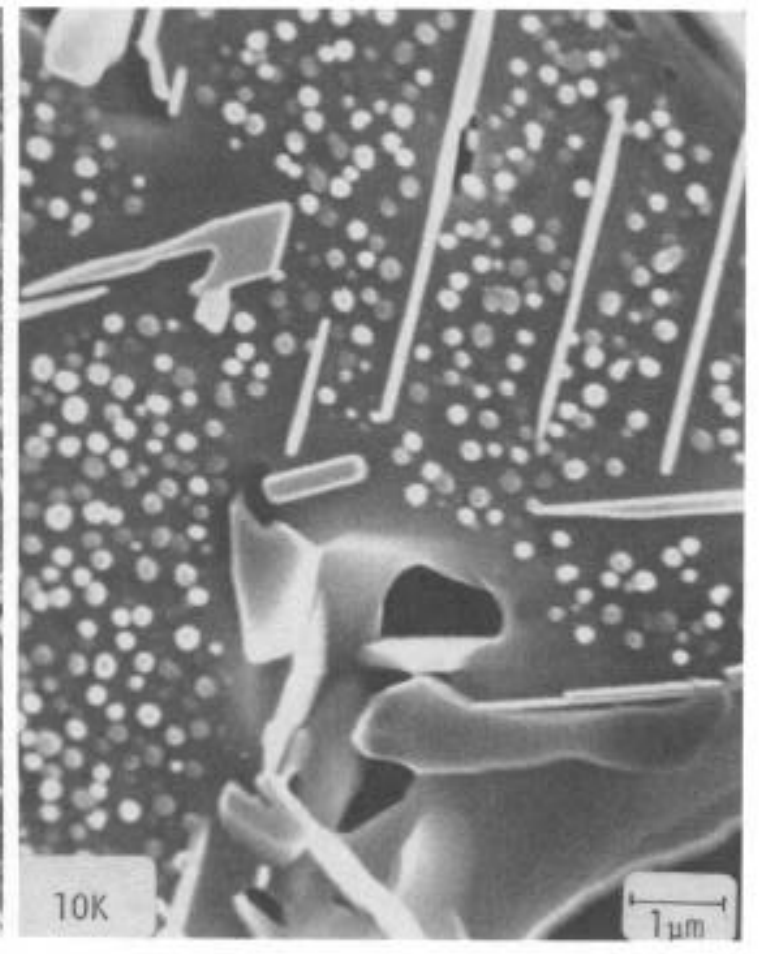

Fig. 9a. S/R $1350^{\circ} \mathrm{F} / 5000 \mathrm{hrs}$.

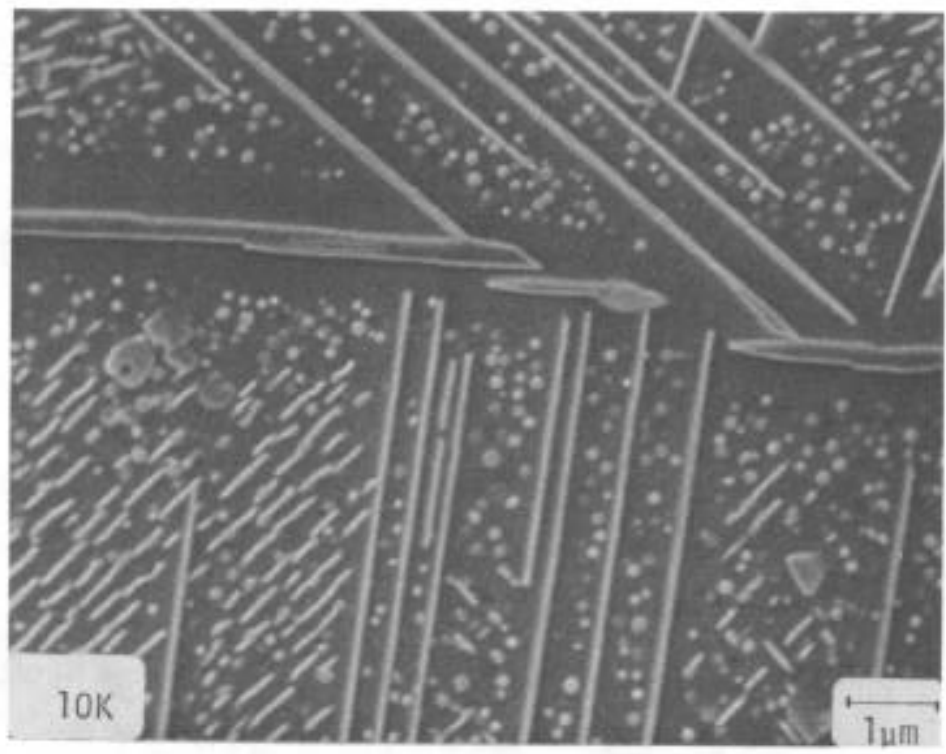

Fig. 10. $\gamma^{\prime \prime}$ to $\delta 1500^{\circ} \mathrm{F} / 100 \mathrm{hrs}$. 
$\tilde{\omega}$

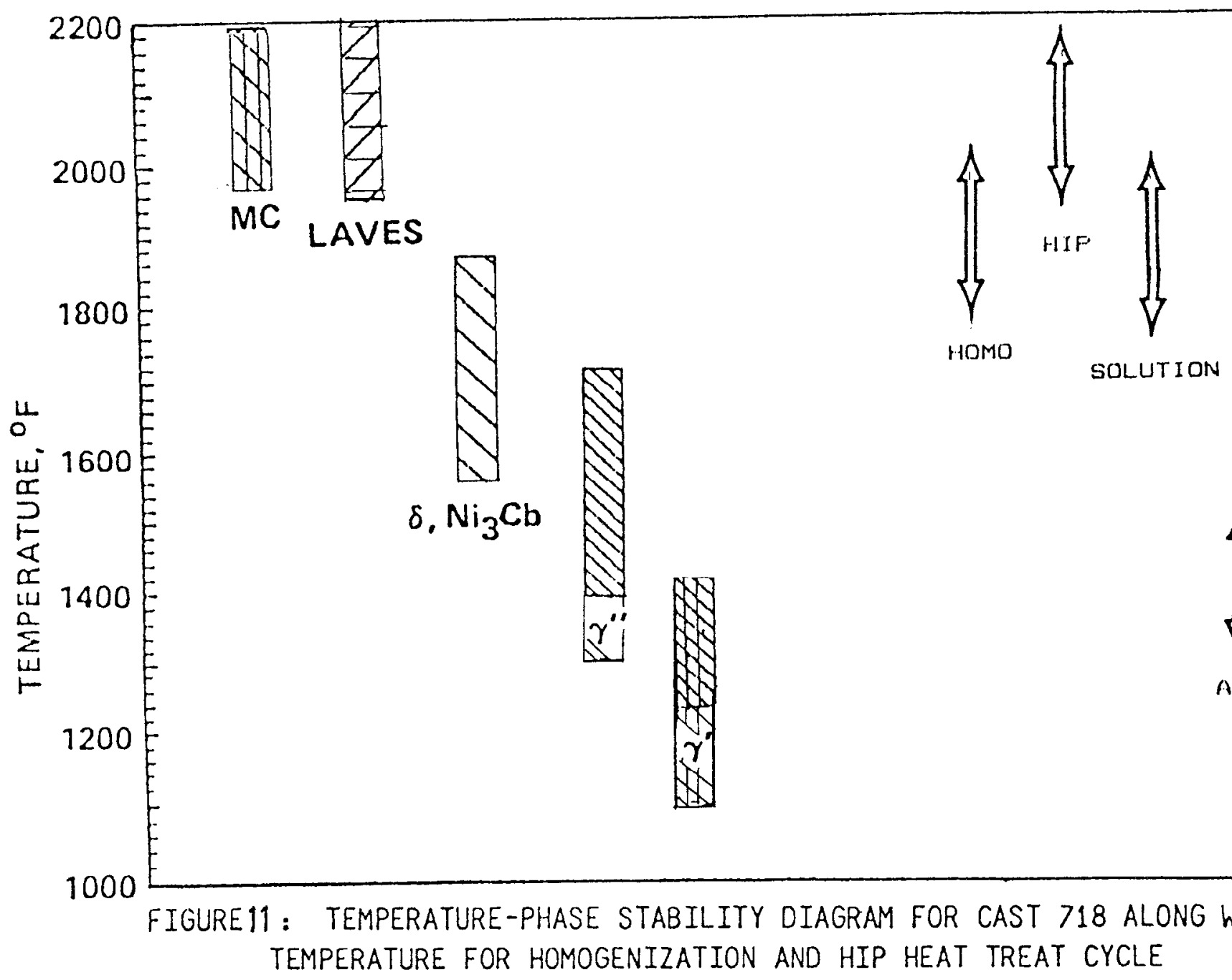


of the material decreases. Although $\gamma$ also is found in areas depleted of $\mathrm{Nb}$ by the formation of the delta phase, the size and number of $\gamma$ particles is inadequate to maintain the strength provided by the initial precipitation of $\gamma^{\prime \prime} / \gamma$. The $\alpha \mathrm{Cr}$ phase forms in the grain boundaries in long time exposures in the temperature range of $1100^{\circ}-1350^{\circ} \mathrm{F}$. The time for the $\alpha \mathrm{Cr}$ precipitation decreases with increasing temperature as large and discrete $\alpha \mathrm{Cr}$ particles have been found in S/R samples after 5000 hours at $1350^{\circ} \mathrm{F}$, Figure 9 . The behavior of $\alpha \mathrm{Cr}$ in 718 at temperatures above $1350^{\circ} \mathrm{F}$ has not been explored since the alloy is used in the $1000^{\circ} \mathrm{F}$ to $1300^{\circ} \mathrm{F}$ temperature range; however, the transition to $\delta$ plates with precipitation of $\gamma$ is seen in 100 hours at $1500^{\circ} \mathrm{F}$, Figure 10.

\section{Conclusions}

During solidification, the $\mathrm{Nb}$, along with $\mathrm{Mo}$ and $\mathrm{Ti}$, segregates heavily to the interdendritic areas where the Laves phase forms. Segregated alloy 718 is homogenized to solution the Laves phase and diffuse the $\mathrm{Nb}$ by high temperature thermal treatments.

The main phases found in cast and wrought 718 are MC, TiN, Laves, delta, $\gamma^{\prime \prime}$ and $\gamma$, phases. The MC and TiN are inert phases while the delta phase is used to control grain size in wrought components and to promote notch ductility. The main strengthening phases are $\gamma^{\prime \prime}$ and $\gamma$ and their precipitation is dependent on the $\% \mathrm{Nb}$, the temperature and time of heat treatment.

The phases found in alloy 718 are plotted in their approximate temperature ranges in Figure 11. The stability of alloy 718 depends on $\gamma^{\prime \prime}$ stability and the time and temperature of exposure. The formation of large amounts of delta phase at the expense of $\gamma^{\prime \prime}$ results in a drop of mechanical properties even though the $\gamma$ phase grows in regions near the delta plates. 